\title{
Synthesis of Novel Well-defined End-functional Macrophotoinitiator of Poly( $\varepsilon$-caprolactone) by Ring-opening Polymerization
}

\author{
Mustafa DEGIRMENCI ${ }^{\dagger}$ \\ Harran University, Faculty of Science, Department of Chemistry, Sanliurfa 63300, Turkey
}

(Received February 24, 2004; Accepted April 16, 2004; Published July 15, 2004)

\begin{abstract}
A new end-chain functional macrophotoinitiator of poly( $\varepsilon$-caprolactone) has been synthesized by controlled/living ring-opening polymerization (ROP) method. For this purpose, mono hydroxy functional a photoinitiator namely, 1-hydroxycyclohexyl phenyl ketone (HCPK), Irgacure 184, was used as the initiator for the stannous-2ethylhexanoate $\left(\mathrm{Sn}(\mathrm{Oct})_{2}\right)$ catalyzed living ring-opening polymerization of $\varepsilon$-caprolactone. The GPC and IR, H NMR, UV and fluorescence spectroscopic studies revealed that low-polydispersity poly( $\varepsilon$-caprolactone) with photoinitiator functionality at the end of the chain was obtained. [DOI 10.1295/polymj.36.542]

KEY WORDS Ring-opening Polymerization / End-functionalization / Macrophotoinitiator / Poly( $\varepsilon$-caprolactone) / Block Copolymer /
\end{abstract}

In recent years, there have been many new developments in the synthesis and photochemical studies of novel photoinitiator molecules. These have been designed to have desirable properties such as higher activity or greater curing speed coupled with lower migration rates and/or water solubility. Two areas of importance in this regard are the development of monomeric and polymeric photoinitiators with reactive functionalities. ${ }^{1}$ Polymers containing photo reactive groups in the main or at the side chains are of great importance due to their application in various fields of UV curing, as precursors for block and graft copolymerization depending on the position of photoinitiators moiety incorporated and the advantages derived from their macromolecular nature, in comparison with their low molecular weight analogues. Many side- and main-chain photoinitiators have been synthesized and their photochemistry and utilization in both applications have been reviewed extensively. ${ }^{2-8}$
Polymeric photoinitiators containing terminal photoactive benzoin groups by using azo-benzoin initiators were synthesized by Yagci et al. ${ }^{6-8}$ The thermal treatment of these initiators in the presence of styrene (St) leads to benzoin groups at both ends of polystyrene chain, as polystyryl radicals tend to terminate via recombination (Scheme 1).

Such photoactive polymers can be used in the preparation of block copolymers of monomers with different chemical nature such as those with liquid crystalline properties. ${ }^{9}$ Similarly, activated monomer (AM) polymerization was used to produce polymers with terminal benzoin groups. ${ }^{10,11}$ The process was easily adapted so that benzoin type photoinitiators containing hydroxyl group were used as initiators in the activated monomer polymerization (Scheme 2).

Quite recently, we applied, ${ }^{12}$ a novel controlled/living polymerization method, atom transfer radical polymerization (ATRP), to incorporate photoinitiator

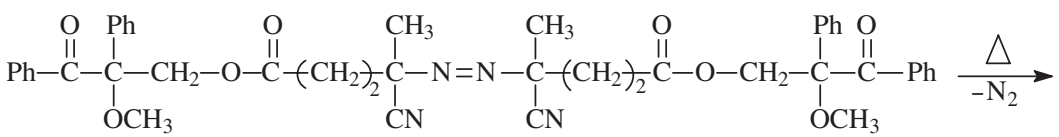<smiles>COC(COC(=O)CC(C)(C)C#N)(C(=O)c1ccccc1)c1ccccc1</smiles>

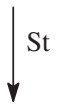<smiles>COC(COC(=O)CCC(C)(C#N)C(CC(C)(C)CCC(=O)OCC(OC)(c1ccccc1)c1ccccc1)c1ccccc1)(C(=O)c1ccccc1)c1ccccc1</smiles>

Scheme 1.

\footnotetext{
${ }^{\dagger}$ To whom correspondence should be addressed (Fax: +90-414-315-1998, E-mail: mustafa@harran.edu.tr).
} 

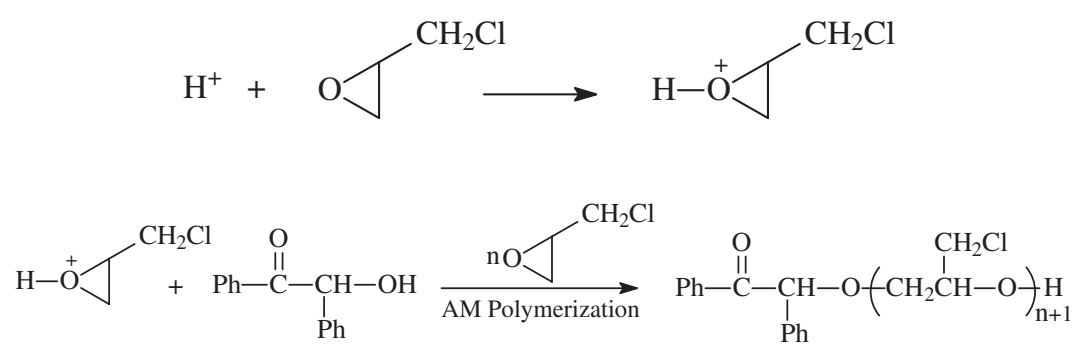

Scheme 2.
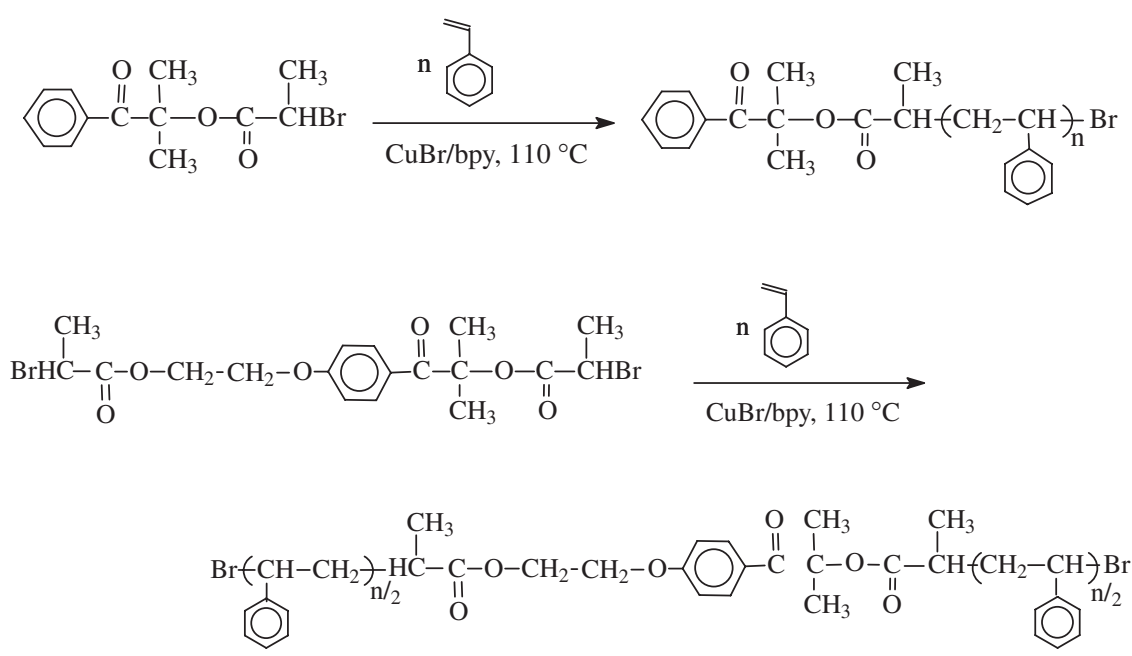

Scheme 3.

moieties into the end- and mid-chain of the polymers. Thus, polystyrenes with precise functionalities and narrow molecular weight distributions were prepared by using respective halide functional initiators in the ATRP system according to Scheme 3.

Ring-opening polymerization (ROP) ${ }^{13,14}$ is the most promising methods in the field of "controlled/living" polymerizations and allow preparation of polymers with precise functionalities, controlled molecular weight and narrow molecular weight distribution. Because of various applications, particularly in biomedical field, homo- and copolymers of polylactones such as poly $(\varepsilon$-caprolactone $)$ receive interest. Tin octoate, $\mathrm{Sn}\left(\mathrm{O}(\mathrm{O}) \mathrm{CCH}\left(\mathrm{C}_{2} \mathrm{H}_{5}\right) \mathrm{C}_{4} \mathrm{H}_{9}\right)_{2}$, in short $\mathrm{Sn}(\mathrm{Oct})_{2}$, is the most widely used ${ }^{15}$ initiator to synthesize designed polymers based on poly( $\varepsilon$-caprolactone). In particular when used in conjunction with hydroxyl functional compounds or prepolymers, telecehelics, linear and star-shaped block copolymers or networks can be obtained ${ }^{16-21}$ via corresponding alkyl octoate formation. The aim of this study was to prepare well-defined, a new kind of end-functional macrophotoinitiator of poly( $\varepsilon$-caprolactone) by using ROP method.

\section{EXPERIMENTAL}

\section{Materials}

1-Hydroxycyclohexyl phenyl ketone (HCPK), Irgacure 184, photoinitiator was received from Ciba Specialty Chemicals and used without further purification. Stannous 2-ethyl-hexanoate (stannous octoate) (Sigma), dichloromethane and methanol (Lab-scan) were used as received. $\varepsilon$-Caprolactone and methyl methacrylate (MMA) (Aldrich) were vacuum distilled over calcium hydride before use.

\section{Ring-opening Polymerization}

Certain amounts of monomer ( $\varepsilon$-caprolactone), stannous octoate and photoinitiator (HCKP) were added under nitrogen in previously flamed and nitrogenpurged schlenk tube equipped with magnetic stirrer. The detailed polymerization conditions are given in Table I. The $\varepsilon$-CL polymerizations were carried out in bulk at $110^{\circ} \mathrm{C}$. After a given time the polymerization was terminated by cooling the tube to the room temperature, then diluted with $\mathrm{CH}_{2} \mathrm{Cl}_{2}$ and poured into 10-fold excess of cold methanol. The polymers were collected after filtration and drying at room temperature in a vacuum for $3 \mathrm{~d}$. 


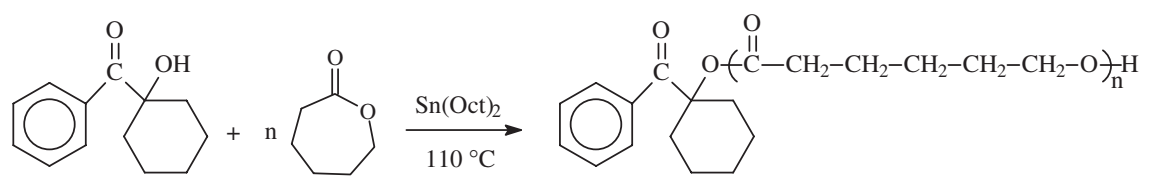

Scheme 4.

Table I. Synthesis of end-functional macrophotoinitiators by ROP ${ }^{\mathrm{a}}$ of $\varepsilon$-Caprolactone

\begin{tabular}{ccccccccr}
\hline Run & $\begin{array}{c}{[\mathrm{I}] \times 10^{2}} \\
\left(\mathrm{~mol} \mathrm{~L}^{-1}\right)\end{array}$ & $\begin{array}{c}\text { Time } \\
(\mathrm{h})\end{array}$ & $\begin{array}{c}\text { Conversion } \\
(\%)\end{array}$ & $M_{\text {ntheo. }}$ & $M_{\mathrm{nGPC}}$ & $M_{\mathrm{w}} / M_{\mathrm{n}}$ & $M_{\mathrm{nH}-\mathrm{NMR}}$ & $M_{\mathrm{nUV}}$ \\
\hline A & 45 & 10 & 100 & 2500 & 2900 & 1.13 & 3650 & 3150 \\
B & 22 & 18 & 100 & 3400 & 3500 & 1.20 & 4200 & 3900 \\
C & 12 & 18 & 52 & 4660 & 4860 & 1.26 & 5100 & 5300 \\
D & 12 & 26 & 82 & 7200 & 6800 & 1.47 & 7550 & 7000 \\
E & 6 & 46 & 98 & 17020 & 16840 & 1.32 & $\mathrm{nd}^{\mathrm{b}}$ & 17500 \\
\hline
\end{tabular}

${ }^{\mathrm{a}}$ Temp. $110{ }^{\circ} \mathrm{C},[\varepsilon-\mathrm{CL}]_{\mathrm{o}}=9.02 \mathrm{~mol} \mathrm{~L}^{-1}$ (in bulk), $[\mathrm{I}] /[\varepsilon-\mathrm{CL}]: 1 / 20$ and $\left[\operatorname{Sn}(\mathrm{Oct})_{2}\right] /[\mathrm{I}]: 1 / 400,{ }^{\mathrm{b}} \mathrm{nd}$ : not determined

\section{Photopolymerization}

Photopolymerization was carried out in $\mathrm{CH}_{2} \mathrm{Cl}_{2}$. Appropriate solutions of monomer (MMA) containing given an amount of macrophotoinitiator (PCL) were placed in a Pyrex tube and degassed with nitrogen prior to irradiation by a merry go round type photoreactor equipped with 16 Philips $8 \mathrm{~W} / 08$ lamps emitting light nominally at $\lambda>300 \mathrm{~nm}$ and a cooling system. At the end of given time, obtained polymer was poured into methanol, filtered, dried and weighted. Conversions were determined gravimetrically.

\section{Characterizations}

IR spectra was recorded on a PerkinElmer spectrum RXI FT-IR spectrophotometer. ${ }^{1} \mathrm{H}$ NMR spectra was recorded on a Bruker $250 \mathrm{MHz}$ spectrometer with $\mathrm{CDCl}_{3}$ as the solvent and tetramethylsilane as the internal standard. UV-vis spectra was recorded on a Shimadzu 1601 spectrophotometer. Fluorescence spectra were registered on a Jasco FP-6300 spectrofluorometer. Elemental analysis results were performed on a CHNS-932 LECO instrument. Gel permeation chromatography (GPC) analyses were performed with a set up consisting of an Agilent 1100 RI apparatus equipped with three Waters ultrastyragel columns (HR series 4, 3, 2 narrow bore), with THF as the eluent at a flow rate of $0.3 \mathrm{~mL} / \mathrm{min}$ and a refractive index detector. Molecular weights of prepolymers (macrophotoinitiator of PCL) were calculated with the aid of polystyrene standards by using following conversion formula: ${ }^{22} M_{\mathrm{PCL}}=0.259 M_{\mathrm{PSt}}{ }^{1.073}$. Molecular weights of homo PMMA and PCL-PMMA block copolymers were calculated by using monodisperse poly(methyl methacrylate) standards.

\section{RESULTS AND DISCUSSION}

It has been shown that $\mathrm{Sn}(\mathrm{Oct})_{2}$ is very effective catalyst for ROP in conjunction with hydroxyl functional compounds. ${ }^{23,24}$ The objective of this work was to use an initiator, with hydroxy functionality so as to produce photo end-functionalized poly( $\varepsilon$-caprolactone). The synthesis of macrophotoinitiator of poly $(\varepsilon$-caprolactone) depicted in Scheme 4, involved the reaction of photoinitiator, namely 1-hydroxycyclohexyl phenyl ketone (HCPK), with $\varepsilon$-caprolactone $(\varepsilon-\mathrm{CL})$ monomer in the presence of stannous octoate catalyst. In view of the reported role of hydroxyl groups as initiators in ring-opening polymerization, this reaction was expected to produce a polymer containing a photoiniator group on one end of the chain, derived from the photoinitiator (Scheme 4).

As can be seen from Table I, the measured and calculated $M_{\mathrm{n}}$ values are in good agreement indicating that the photoinitiator added to the solution generates one growing end. By modifying the initiator concentration and polymerization time, end-functional macroinitiators with various molecular weights and low polydispersities were obtained. Some discrepancy observed with the values calculated by spectral methods may be due to the inaccuracy of the molecular weight determination by end-group analysis.

The GPC traces are unimodal and narrow indicating that no side reactions occurred. Moreover, dual detection by refractive index and UV measurements provides clear evidence for the complete functionalization. As can be seen from Figure 1, GPC trace of $\operatorname{poly}(\varepsilon$-caprolactone $)$ measured by UV $(\lambda=320 \mathrm{~nm})$ and refractive index appear at the same elution volume. 


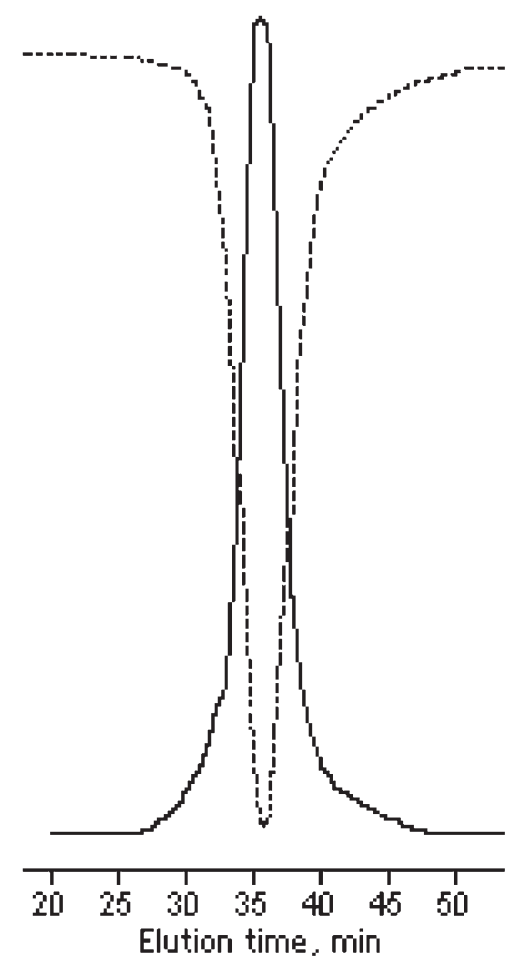

Figure 1. GPC trace of PCL; refractive index signal (-) and UV signal at $\lambda=320 \mathrm{~nm}(---)$ (Table I, Run A).

The structure of the new macrophotoinitiator of PCL was confirmed by spectroscopic investigations. The IR spectra contain the characteristic CO ester band and the CO keto group of the photoinitiator moiety at 1732 and $1684 \mathrm{~cm}^{-1}$, respectively (Figure 2). In the ${ }^{1} \mathrm{H}$ NMR spectra of the polymer samples can be found not only the specific signals of poly( $\varepsilon$-caprolactone) (PCL), but also absorptions belonging to the rests of initiator. In Figure 3 is shown the ${ }^{1} \mathrm{H}$ NMR spectra recorded in $\mathrm{CDCl}_{3}$ evidenced resonance signals of protons of relative intensities corresponding to the number and type of protons.

The incorporation of photoinitiator group into polymers was also evidenced by UV absorption measurements. Figure 4 shows the absorption spectra of precursor, HCKP, together with the PCL obtained. It can be seen that polymeric photoinitiators have spectra which are typical for benzoyl chromophores absorbing strongly in far UV and possessing an absorption maximum of the $\mathrm{n} \rightarrow \pi^{*}$ transitions around 320 $\mathrm{nm}\left(\lambda_{\max } \approx 320 \mathrm{~nm}, \varepsilon \approx 100-200 \mathrm{~L} \mathrm{~mol}^{-1} \mathrm{~cm}^{-1}\right) .{ }^{25}$ Thus they are suitable for use in formulations which do not absorb strongly in this region.

Figure 5 shows the fluorescence emission of the related molecules (HCKP and PCL) in chloroform at room temperature. Both spectra show the vibrational structures of the phenyl ketone chromophore. These spectroscopic investigations suggest that the photochromophoric phenyl ketone groups were conserved under the polymerization conditions.

Even more convincing evidence for the presence of the photoinitiator group at the end-chain of polymers was obtained from the experiments on the polymerization of methyl methacrylate (MMA). Typical results concerning photochemically induced polymerization of methyl methacrylate (MMA) in $\mathrm{CH}_{2} \mathrm{Cl}_{2}$ at $25^{\circ} \mathrm{C}$ by using PCL photoinitiators are shown in Table II. It should be pointed out that a control experiment without a polymeric initiator gave only negligible amount of polymer after the same irradiation time. UV irradiation of the polymeric photoiniator caused

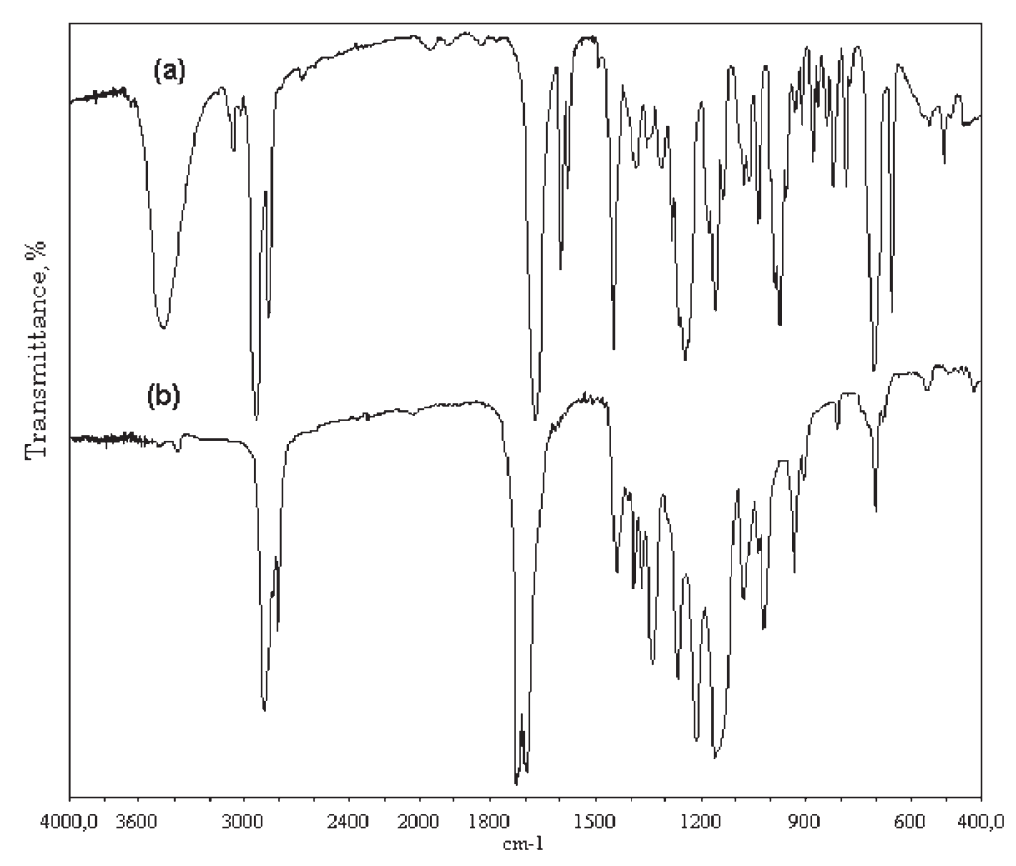

Figure 2. IR spectra of HCPK (a) and PCL (b). 

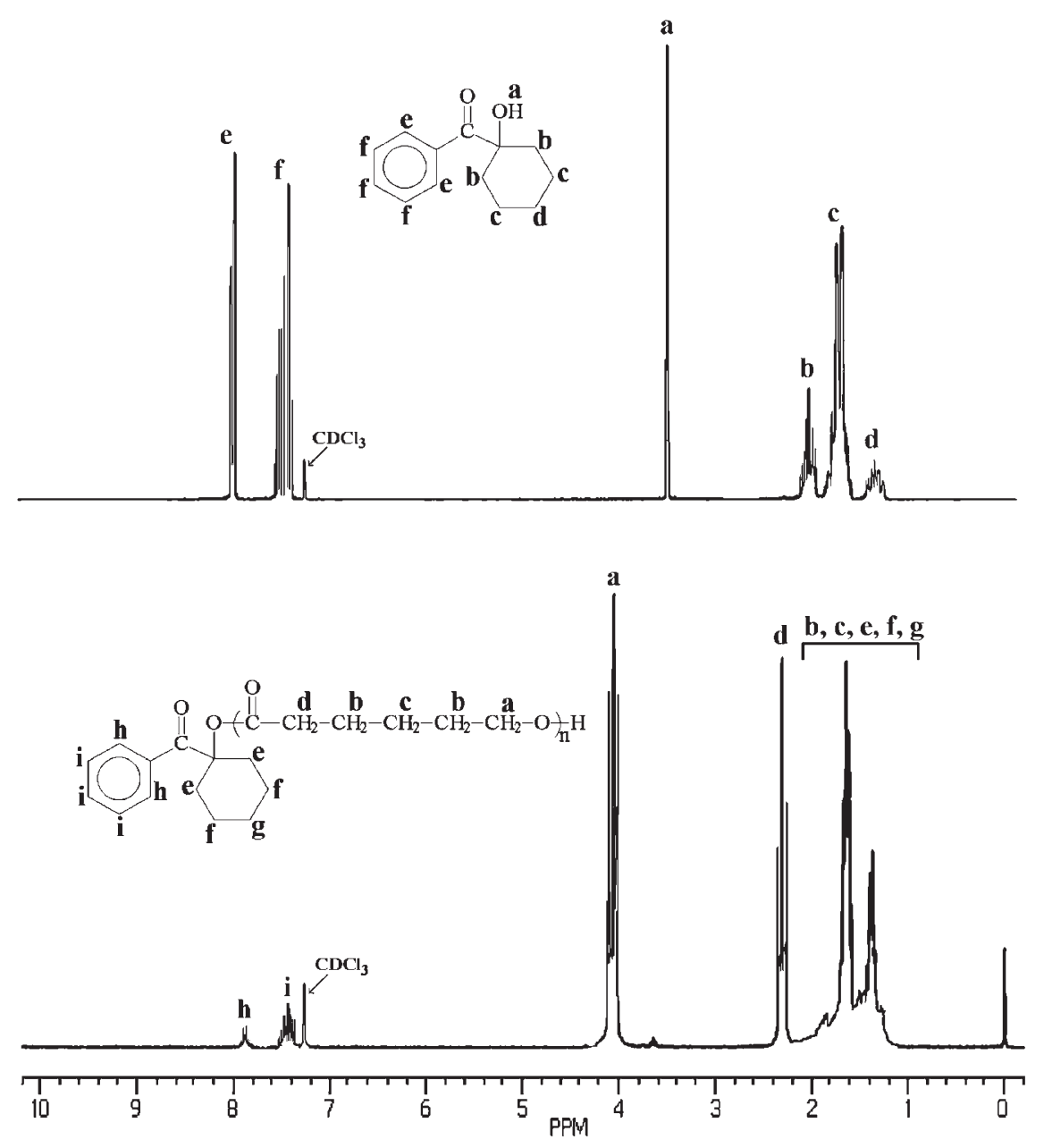

Figure 3. ${ }^{1} \mathrm{H}$ NMR spectra of $\mathrm{HCPK}$ (a) and PCL (Table I, Run A) (b) in $\mathrm{CDCl}_{3}$.

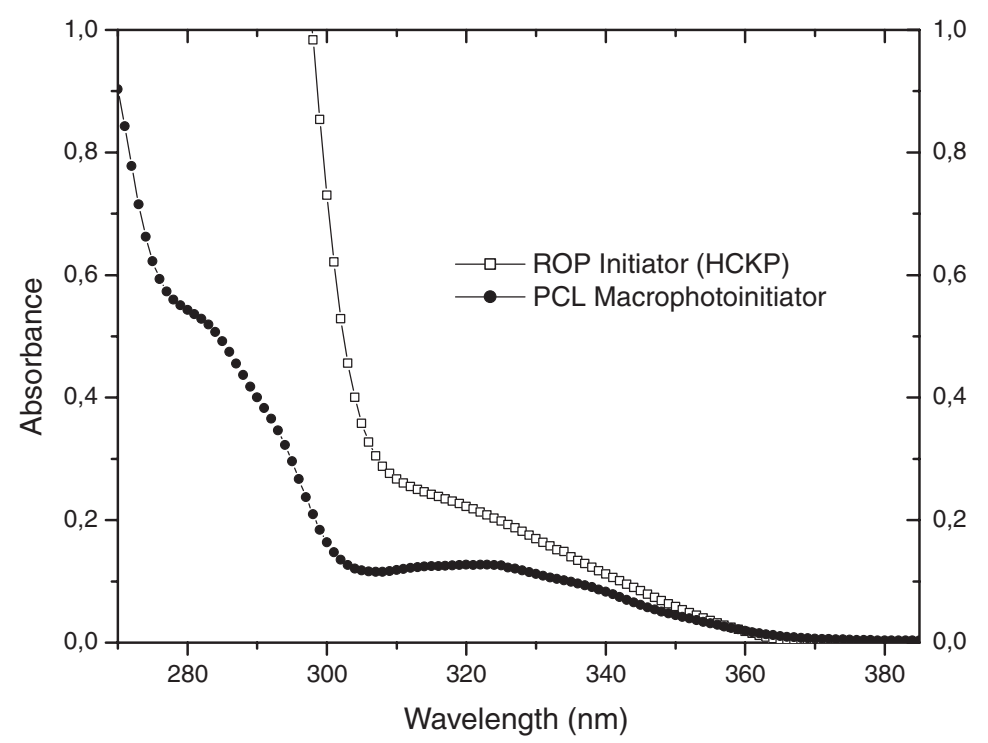

Figure 4. Absorption spectra of $\operatorname{HCPK}\left(4.16 \times 10^{-3} \mathrm{~mol} \mathrm{~L}^{-1}\right)$ and PCL $\left(2.10 \mathrm{~g} \mathrm{~L}^{-1}\right)$ (Table I, Run B) in $\mathrm{CHCl}_{3}$.

$\alpha$-scission and yielded benzoyl, and polymer bound radicals, according to the following reaction. Both of these radicals may then initiate the polymerization of MMA, therefore homo poly(methyl methacrylate) formation is inevitable.

Figure 6 shows the GPC chromatograms of PCL macrophotoinitiator and block copolymer (PCL- $b$ PMMA) formed there from. The new peak at lower 


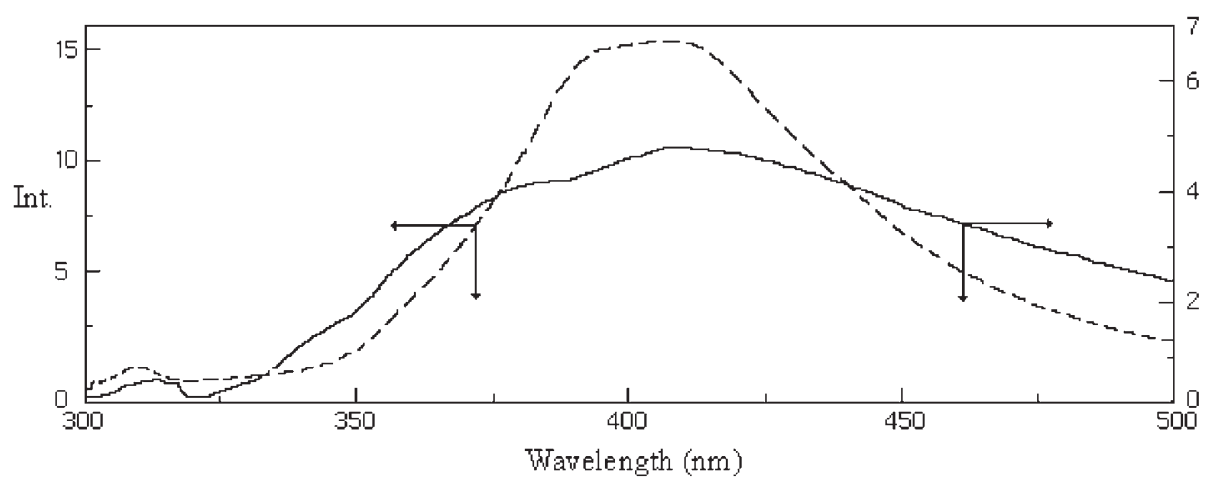

Figure 5. Fluorescence spectra of $\mathrm{HCPK}\left(2.7 \times 10^{-3} \mathrm{~mol} \mathrm{~L}^{-1}\right)(---)$ and PCL $\left(15.32 \mathrm{~g} \mathrm{~L}^{-1}\right)$, (Table I, Run B) (-) in CHCl $\lambda_{\mathrm{exc}}=320 \mathrm{~nm}$.

Table II. Photoinduced polymerization MMA (in $\left.\mathrm{CH}_{2} \mathrm{Cl}_{2}\right)\left(4.71 \mathrm{~mol} \mathrm{~L}^{-1}\right)$ by using poly $\left(\varepsilon\right.$-caprolactone) $\left(50.6 \mathrm{~g} \mathrm{~L}^{-1}\right)$ macrophotoinitiators at room temp. $\lambda_{\text {inc }}>300 \mathrm{~nm}$

\begin{tabular}{|c|c|c|c|c|c|c|c|c|c|}
\hline \multirow{2}{*}{ Run } & \multirow{2}{*}{ PCL } & \multirow{2}{*}{$\begin{array}{l}\text { Irradiation } \\
\text { time (min) }\end{array}$} & \multirow{2}{*}{$\begin{array}{c}\text { Conv }^{\mathrm{a}} \\
(\%)\end{array}$} & \multicolumn{3}{|c|}{ Homo PMMA } & \multicolumn{3}{|c|}{ PCL- $b$-PMMA } \\
\hline & & & & $(\%)$ & $\left(M_{\mathrm{n}} \times 10^{-3}\right)^{\mathrm{b}}$ & $M_{\mathrm{w}} / M_{\mathrm{n}}$ & $(\%)$ & $\left(M_{\mathrm{n}} \times 10^{-3}\right)^{\mathrm{b}}$ & $M_{\mathrm{w}} / M_{\mathrm{n}}$ \\
\hline $\mathrm{F}$ & Run A & 150 & 9 & 46 & 6 & 1.65 & 54 & 102 & 1.87 \\
\hline $\mathrm{G}$ & Run B & 180 & 11 & 48 & 6.8 & 1.62 & 52 & 94 & 1.90 \\
\hline $\mathrm{H}$ & Run C & 180 & 12 & 49 & 9 & 1.65 & 51 & 93 & 1.84 \\
\hline
\end{tabular}

${ }^{\mathrm{a}}$ MMA conversion ${ }^{\mathrm{b}}$ Determined by GPC according PMMA standards

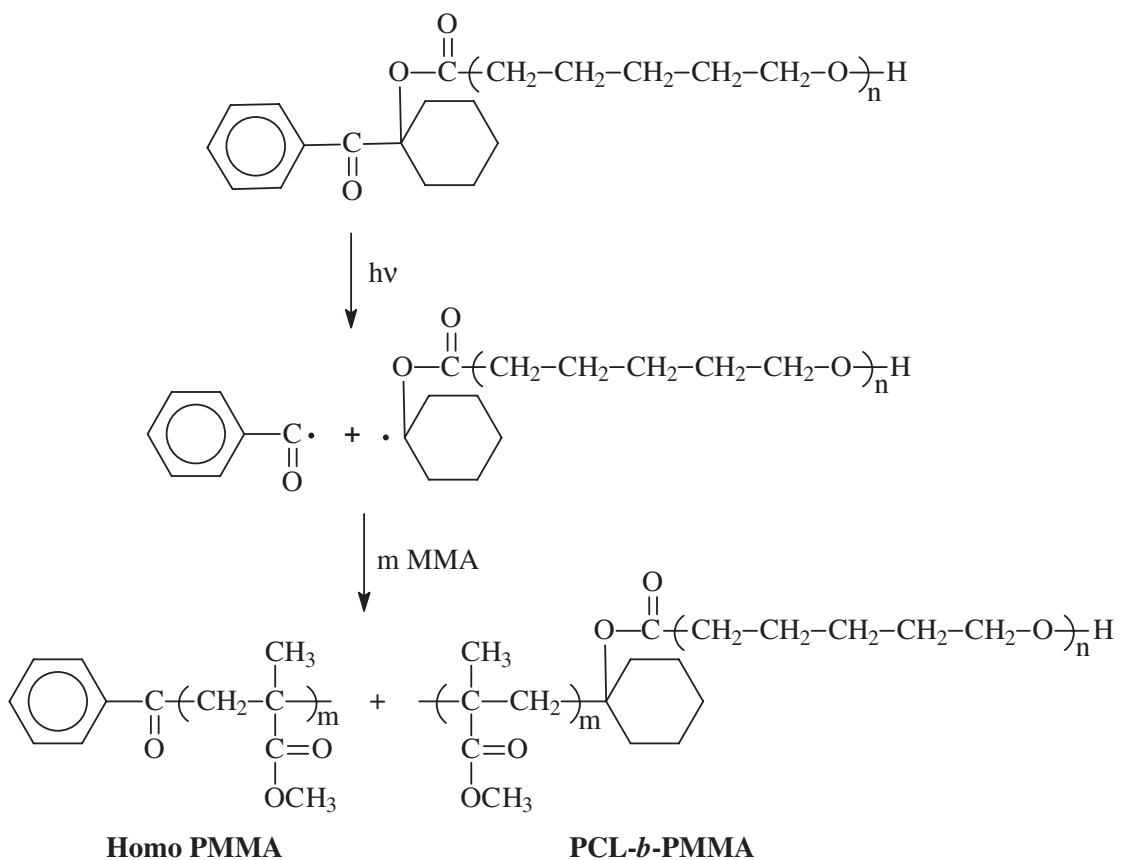

Scheme 5.

elution volume is ascribed to the block copolymer.

Irradiation in the presence of $5 \times 10^{-2} \mathrm{~mol} \mathrm{~L}^{-1}$ hydroquinone as the radical scavenger, failed to produce any polymer under the same experimental conditions. These results confirm that the chains are quantitatively functionalized to generate the desired end-functional PCL macrophotoinitiators.

In conclusion, a novel well-defined end-functional macrophotoinitiator of poly( $\varepsilon$-caprolactone) was prepared by ROP method. Characterization of the macrophotoinitiators by ${ }^{1} \mathrm{H}$ NMR, UV and fluorescence spectroscopy and GPC showed complete functionalization of PCL. Such prepared narrowly distributed a macrophotoinitiator can be used in photopolymerization of vinyl monomers such as MMA. Further studies on the use of these polymers as a precursor in photo- 


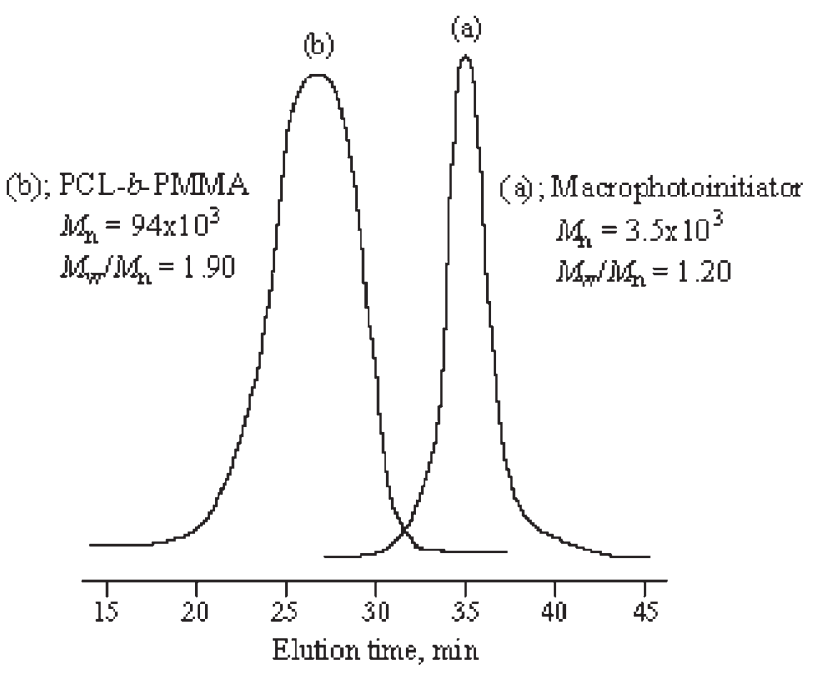

Figure 6. GPC traces of PCL, (a) and PCL-PMMA block copolymer (Table II, Run G) (b).

induced free radical promoted cationic polymerization for preparing block copolymers of cationic polymerizable monomers are now in progress.

Acknowledgment. The author would like to thank Harran University, Sanliurfa, Turkey, Research Fund (HÜBAK) for financial support.

\section{REFERENCES}

1. N. S. Allen, Ed., "Photopolymerization and Photoimaging Science and Technology,” Elsevier, Oxford, U.K., 1989.

2. T. Corrales, F. Catlina, C. Peinado, and N. S. Allen, J. Photochem. Photobiol., A, 159, 103 (2003).

3. C. Carlini and L. Angiolini, Adv. Polym. Sci., 123, 12 (1995).

4. R. S. Davidson, J. Photochem. Photobiol., A, 69, 263 (1993).

5. Y. Yagci, Macromol. Symp., 161, 19 (2000).

6. K. Dietliker, "Chemistry and Technology of UV\&EB Formulation for Coatings, Inks\&Paints," SITA Technology
Ltd., London, U.K., 1991, Vol. III.

7. Y. Yagci in "Macromolecular Engineering: Recent Aspects," M. K. Mishra, O. Nuyken, S. Kobayashi, and Y. Yagci, Ed., Plenum Press, New York, N.Y., 1995, Chap. 11.

8. Y. Yagci and W. Schanbel, Prog. Polym. Sci., 15, 551 (1990).

9. G. Galli, E. Chiellini, Y. Yagci, I. E Serhatli, M. Laus, and A. S. Angeloni, Macromol. Symp., 107, 85 (1996).

10. Y. Yagci, Y. Hepuzer, A. Onen, I. E. Serhatli, P. Kubisa, and T. Biedron, Polym. Bull., 33, 411 (1994).

11. Y. Hepuzer, Y. Yagci, T. Biedron, and P. Kubisa, Angew. Macromol. Chem., 237, 163 (1996).

12. M. Degirmenci, I. Cianga, and Y. Yagci, Macromol. Chem. Phys., 203, 1279 (2002).

13. A. Löfgren, A. C. Albertsson, P. Dubois, and R. Jerome, J. Macromol. Sci., Part C: Rev. Macromol. Chem. Phys., 35, 379 (1995).

14. D. Mecerreyes, R. Jerome, and P. Dubois, Adv. Polym. Sci., 147, 1 (1999).

15. A. Kowalski, A. Duda, and S. Penczek, Macromol. Rapid Commun., 19, 567 (1998).

16. Y. K. Choi, Y. H. Bae, and S. W. Kim, Macromolecules 31, 8766 (1998).

17. C. Kim, S. C. Lee, I. C. Kwon, H. Chung, and S. Y. Jeong, Macromolecules 35, 193 (2002).

18. Z. Guo, D. Wan, and Z. Huang, Macromol. Rapid Commun., 22, 367 (2001).

19. R. F. Storey and T. P. Hickey, Polymer 35, 830 (1994).

20. R. F. Storey, J. S. Wiggins, and A. D. Puckett, J. Polym. Sci., Polym. Chem. Ed., 32, 2345 (1994).

21. R. F. Storey, S. C. Warren, C. J. Allison, J. S. Wiggins, and A. D. Pucket, Polymer 34, 4365 (1993).

22. P. Dobis, I. Barakat, R. Jerome, and P. Teyssie, Macromolecules, 26, 4407 (1993).

23. A. Kowalski, A. Duda, and S. Penczek, Macromolecules, 33, 7359 (2000).

24. H. R. Kricheldorf, S. I. Kreiser, and A. Stricker, Macromolecules, 33, 702 (2000).

25. J. V. Crivello and K. Dietliker, in "Photoinitiators for Free Radical, Cationic \& Anionic Photopolymerization," 2nd ed., G. Bradley, Ed., John Wiley \& Sons, Chichester, U.K., 1998, p 115. 